\title{
Characterization of Insulin Adsorption Behavior on Amphoteric Charged Membranes
}

\author{
By Shaoling Zhang, Keiichiro SAITo, Hidetoshi Matsumoto, \\ Mie MINAGAWA, and Akihiko TANIOKA*
}

With view to develop an amphoteric charged membrane for drug delivery, we have studied the adsorption of insulin on it. In the present study, the amphoteric charged membranes were prepared by pore-surface modification of porous poly(acrylonitrile) (PAN) membranes by grafting with acrylic acid (AAc) and/or $N, N$-(dimethylamino)propyl acrylamide (DMAPAA). Their surface charge properties and the insulin adsorption behaviors were investigated by zeta potential measurement and UV spectrophotoscopy, respectively, at different pHs. The equilibrium adsorbed amount of insulin correlates well with the charge properties of the membranes and insulin, which indicates that electrostatic interaction played an important role in the insulin adsorption. In addition, adsorption kinetics changed from a Fickian mode to a non-Fickian one when adsorbed amount increased to very high values.

KEY WORDS: Insulin / Poly(acrylonitrile) / Amphoteric Charged Membrane / Zeta Potential / Adsorption /

Insulin is a polypeptide hormone produced by the pancreatic $\beta$ cells, and regulates carbohydrate homeostasis. Currently, the administration of insulin through parenteral injection (e.g., subcutaneous injection) is the commonest therapy of diabetes. Since pain and risk for infection cannot be completely avoided in this method, novel non-invasive insulin delivery techniques such as iontophoresis have been required. $^{1-5}$

The adsorption of proteins on biomaterial surfaces has been widely studied, ${ }^{6-10}$ and it has been identified to be very complex and can be influenced by a lot of factors such as electrostatic interactions and hydrophilicity/hydrophobicity. Protein adsorption on membranes not only could change the pore size and charge property of the membrane but also could give valuable information for the study of the protein transport mechanism within the membrane. ${ }^{6,11,12}$ There have been, however, few reports on the relationship between insulin adsorption on and transport through a membrane for the drug delivery. It is of great interest to study the insulin adsorption behavior on the charged membranes for the administration of insulin release.

Recently, amphoteric charged membranes have attracted considerable interests due to their $\mathrm{pH}$-responsibility, antifouling property, flexibility in the design of charge structure, and they are expected to be applied in various fields such as proteins separation and drug delivery systems. ${ }^{11,13-16}$ In the present study, a series of amphoteric charged membranes with different ratios of acidic to basic groups were prepared, and the insulin adsorption on the prepared membranes was investigated at different pHs. The aim of this study is to investigate the relationship between the insulin adsorption behavior and the surface charge property of the amphoteric charged membranes for drug delivery.

\section{EXPERIMENTAL}

\section{Materials}

Poly(acrylonitrile) (PAN, $\left.M_{\mathrm{w}} 410,000 \mathrm{Da}\right)$ and poly(vinylpyrrolidone) (PVP, $M_{\mathrm{w}} 40,000 \mathrm{Da}$ ) were provided by Mitsubishi Rayon, Japan and Wako Pure Chemical Industries, Japan, respectively. Recombinant human insulin $\left(M_{\mathrm{w}} \sim\right.$ $6000 \mathrm{Da}$, isoelectric point (IEP) $\sim 5.4$ ) was obtained from Wako Pure Chemical Industries, Japan. N,N-dimethylformamide (DMF), Acrylic acid (AAc, $\left.\mathrm{p} K_{\mathrm{a}}=4.26\right), N, N$-(dimethylamino)propyl acrylamide (DMAPAA, $\mathrm{p} K_{\mathrm{a}}=10.35$ ), ferrous sulfate, hydrogen peroxide, sodium bisulfite, ammonium persulfate (APS), $N, N, N^{\prime}, N^{\prime}$-tetramethyl-ethylenediamine (TMEDA), glycerol were purchased from Wako Pure Chemical Industries, Japan. These reagents were of extra-pure grade and were used without further purification.

\section{Membrane Preparation}

Porous PAN membranes were prepared by phase inversion method, and then modified by grafting with AAc and/or DMAPAA as described in our previous papers. ${ }^{13,17}$ Singlecharged membranes were prepared by graft polymerization with the initiation of redox systems $-\mathrm{Fe}^{2+}-\mathrm{H}_{2} \mathrm{O}_{2}$ for AAc and $\mathrm{NaHSO}_{3}-\left(\mathrm{NH}_{4}\right)_{2} \mathrm{~S}_{2} \mathrm{O}_{8}$ for DMAPAA. The amphoteric charged membranes were prepared by a radical reaction with APS as initiator and TMAEDA as additive. After grafting, the membranes were washed sufficiently with $1 \mathrm{mM} \mathrm{HCl}$ and $0.1 \mathrm{mM} \mathrm{NaOH} \sim \mathrm{NaOH}$, respectively. The degree of graft polymerization (DG) was estimated using eq 1 .

$$
D G=\frac{W_{2}-W_{1}}{W_{1}}
$$


Table I. Physicochemical properties of the prepared membranes

\begin{tabular}{|c|c|c|c|c|c|c|c|}
\hline \multirow{2}{*}{$\begin{array}{c}\text { Sample } \\
\text { membrane }\end{array}$} & \multirow{2}{*}{$\begin{array}{c}\text { Monomer } \\
\text { feed } \\
\text { ratio }^{\mathrm{a}}\end{array}$} & \multirow{2}{*}{$\begin{array}{c}D G \\
(w t \%)\end{array}$} & \multirow{2}{*}{$\begin{array}{l}\text { Contact } \\
\text { angle } \\
\left({ }^{\circ}\right)^{\mathrm{b}}\end{array}$} & \multirow{2}{*}{$\begin{array}{c}\text { Hydraulic } \\
\text { permeability } \\
\left(\mathrm{mL} / \mathrm{m}^{2} \cdot \mathrm{h} \cdot \mathrm{cm} \mathrm{H}_{2} \mathrm{O}\right)\end{array}$} & \multirow{2}{*}{$\begin{array}{l}\text { Pore } \\
\text { size }^{d} \\
(n m)\end{array}$} & \multicolumn{2}{|c|}{$\begin{array}{l}\text { Zeta potential } \\
\qquad(\mathrm{mV})^{\mathrm{e}}\end{array}$} \\
\hline & & & & & & pH 3.3 & $\mathrm{pH} 7.4$ \\
\hline AAc-grafted & $100: 0$ & 0.53 & 52 & 695 & 12.7 & -4.4 & -6.1 \\
\hline Amphoteric-1 & $80: 20$ & 0.63 & 53 & 884 & 13.5 & 0.3 & -5.1 \\
\hline Amphoteric-2 & $55: 45$ & 0.90 & 52 & 758 & 13.0 & 4.8 & -0.8 \\
\hline Amphoteric-3 & $30: 70$ & 1.16 & 57 & 616 & 12.3 & 7.2 & 1.7 \\
\hline DMAPAA-grafted & $0: 100$ & 0.97 & 59 & 584 & 12.1 & 8.0 & 4.4 \\
\hline Unmodified PAN & - & - & 56 & 1895 & $16.3^{c}$ & -1.8 & -5.1 \\
\hline
\end{tabular}

${ }^{a}$ Molar ratio of AAc to DMAPAA. ${ }^{b}$ Measured with deionized water at $\mathrm{pH} 5.6$ with the dynamic sessile drop method. ${ }^{\mathrm{c}}$ Measured by the capillary condensation method. ${ }^{d}$ Estimated according to the Hagen-Poisseuille equation. ${ }^{e}$ Obtained from zeta potential measurement.

where $W_{1}$ and $W_{2}$ are the weights of the dried membranes before and after graft polymerization, respectively.

\section{Characterization of the Prepared Membranes}

Hydraulic Permeability Measurement. The hydraulic permeability of the membranes was calculated from the flow rate of deionized water at $25^{\circ} \mathrm{C}$, with a constant pressure difference $0.1 \mathrm{MPa}$ across the membrane. The membrane area exposed to the flow was $3.8 \mathrm{~cm}^{2}$. Pore sizes of the membranes can be estimated from the hydraulic permeability according to the Hagen-Poiseuille equation. ${ }^{5,15}$ In our case, by assuming that the pore number and thickness of the membrane did not change after grafting, the pore sizes of the grafted membranes were estimated by eq 2 .

$$
\frac{J}{J_{0}}=\left(\frac{r}{r_{0}}\right)^{4}
$$

where $J_{0}$ and $r_{0}$ are the hydraulic permeability and pore size of the unmodified PAN membrane, respectively. $r_{0}$ was measured by the capillary condensation method as $16.3 \mathrm{~nm}$.

Water Contact Angle Measurement. The contact angles of the water droplets were measured by the sessile drop method using a contact angle measurement system (DropMaster 500, Kyowa Interface Science, Japan). The weight of the water droplets for the measurements was $2 \mathrm{mg}$. All measurements were carried out at five or more different points for each sample at $25 \pm 1{ }^{\circ} \mathrm{C}$ and were reproducible within $3^{\circ}$.

Zeta Potential Measurement. The streaming potential measurement was done using an electrokinetic analyzer (SurPASS, Anton Paar GmbH, Austria) equipped with a Clamping Cell. ${ }^{18}$ A pair of the prepared membranes having an area of $25 \times 55 \mathrm{~mm}^{2}$ were placed in the measuring cell. The membranes were separated by a spacer that forms a streaming channel. The streaming potential was detected by the $\mathrm{Ag} / \mathrm{AgCl}$ electrodes. A background electrolyte of $1 \mathrm{mM} \mathrm{KCl}$ solution was used and the $\mathrm{pH}$ was adjusted with $0.1 \mathrm{M} \mathrm{HCl}$ and $0.1 \mathrm{M}$ $\mathrm{NaOH}$. The zeta potential was obtained from the streaming potential using eq 3 .

$$
\zeta=\frac{d U_{s t r}}{d p} \frac{\eta \kappa}{\varepsilon_{0} \varepsilon_{r}}
$$

where $U_{s t r}$ is the streaming potential, $p$ is the pressure drop across the streaming channel, $\varepsilon_{0}$ is the vacuum permittivity $\left(8.854 \times 10^{-12} \mathrm{~J}^{-1} \mathrm{C}^{2} \mathrm{~m}^{-1}\right), \varepsilon_{r}$ is the dielectric constant of the solution (78.3), $\eta$ is the solution viscosity ( $0.8902 \mathrm{mPas})$, and $\kappa$ is the electrical conductivity of the bulk solution.

Adsorption Measurement. The freeze-dried test membrane was first immersed in a buffer solution for one day and then soaked in $10 \mathrm{~mL}$ of $0.22 \mathrm{mg} / \mathrm{mL}$ insulin solution. The UV absorption intensity of the insulin solution was measured by a UV-Vis spectrophotometer (U-2000, Hitachi, Japan) at $276 \mathrm{~nm}$. The concentration of insulin in the solution was determined by the calibration curves. The adsorbed amount of insulin was estimated from the decrease of insulin amount in the solution. The adsorbed insulin onto the vessel was deduced as a blank. All adsorption experiments were carried out at $37^{\circ} \mathrm{C}$.

\section{RESULTS AND DISCUSSION}

\section{Physicochemical Properties of the Prepared Membranes}

Physicochemical properties of the prepared membranes were summarized in Table I. After grafting, hydraulic permeability of the membranes decreased, and the grafted membranes have smaller pore sizes than the unmodified PAN membrane. This suggests that the functional monomers were grafted onto the membrane pore surface. However, all of the grafted membranes have a similar water contact angle with the unmodified PAN membrane. As functional monomers, both AAc and DMAPAA have hydrophilic charge groups, and there are reports that the water contact angle of the membrane decreased with degree of grafting until a constant value. ${ }^{19-22}$ Therefore, the similar water contact angle before and after modification is possibly due to the relatively low degree of grafting. Another possible reason in our case is that the water contact angle of the unmodified PAN membrane is in the same range as that of the reported AAc and DMAPAA grafted membranes, so the effect of graft polymerization on the water contact angle of the membranes is not remarkable.

The zeta potential of the membranes grafted with AAc and/ or DMAPAA varied with $\mathrm{pH}$. The AAc-grafted membrane that had functional anionic groups showed negative charge at both pH 3.3 and 7.4, and the zeta potential was more negative at higher $\mathrm{pH}$ due to the dissociation of the carboxylic groups. In the case of the DMAPAA-grafted membrane that had functional cationic charge groups, the zeta potential was always positive, and larger values appeared at lower $\mathrm{pH}$ due to the 
existence of amine groups. For the amphoteric membranes, their zeta potential depended on the ratio of AAc to DMAPAA, and it can be seen that the zeta potential increased with the DMAPAA ratio in the grafting feed solution. This demonstrates that the surface charge of the amphoteric charged membranes can be designed by controlling the ratio of AAc to DMAPAA. Here we should note that besides the ratio of AAc to DMAPAA, the conformation of the grafted polyelectrolyte chains and the degree of graft can also influence the zeta potential of the membranes. ${ }^{13,15}$ Additionally, the zeta potential of the unmodified PAN membrane was also measured and it turned to be negative at both $\mathrm{pHs}$, although this membrane has no charge groups. Similar phenomena have been found, and it is ascribed to the specific adsorption of electrolyte anions onto the membrane surface. ${ }^{13,23}$

\section{Equilibrium Adsorbed Amount}

The adsorption measurements were conducted at different pHs. Since the IEP of insulin is about 5.4, two kinds of $\mathrm{pH}$ conditions, $\mathrm{pH} 3.3$ (pH lower than the IEP, $10 \mathrm{mM}$ acetic acid buffer) and $\mathrm{pH} 7.4$ (pH higher than the IEP and the physiological $\mathrm{pH}, 10 \mathrm{mM}$ Tris- $\mathrm{HCl}$ buffer), were used (We cannot prepare insulin solution near $\mathrm{pH} 5.4$ due to the aggregation of insulin). The reported zeta potential values of insulin at these two pHs are about $33 \mathrm{mV}$ and $-65 \mathrm{mV}$, respectively. ${ }^{24}$ Figure 1 shows the effect of $\mathrm{pH}$ on the insulin equilibrium adsorbed amount onto the prepared membranes.

At pH 3.3 (Figure 1(a)), the AAc-grafted membrane was negatively charged and the other grafted membranes and insulin were positively charged. Insulin adsorbed on the oppositely (negatively) charged AAc-grafted membrane and the Amphoteric-1 membrane with almost neutral charge. At pH 7.4 (Figure 1(b)), the physiological pH condition, on the other hand, the DMAPAA-grafted membrane and the Amphoteric-3 membrane were positively charged and the other grafted membranes and insulin were negatively charged. Adsorbed amount of insulin on the grafted membranes decreased with the zeta potential value from +4.4 to $-6.1 \mathrm{mV}$. These results show that the electrostatic effect (attractive or repulsive) is an important factor for insulin adsorption, and higher equilibrium adsorption amount appeared when insulin and the membrane carried opposite charge.

Besides electrostatic interaction, other factors like the hydrophobic interaction between the membrane and insulin may also contribute to the insulin adsorption. ${ }^{8,25}$ For the unmodified PAN membrane, because it had no charge groups, its insulin adsorption amount was less dependent on $\mathrm{pH}$, and the adsorption of insulin was mainly due to the hydrophobic interaction. Also, for the membranes with almost neutral charge (i.e., Amphoteric-1 membrane at $\mathrm{pH} 3.3$ and the Amphoteric-2 membrane at $\mathrm{pH} 7.4$ ), the insulin adsorption could be ascribed to the contribution of hydrophobic interaction. In addition, the insulin adsorption on the AAc-grafted membrane at $\mathrm{pH} 7.4$ seems to contradict the electrostatic interaction; even though both the insulin and the AAc-grafted membrane were negatively charged at $\mathrm{pH} 7.4$, there was still

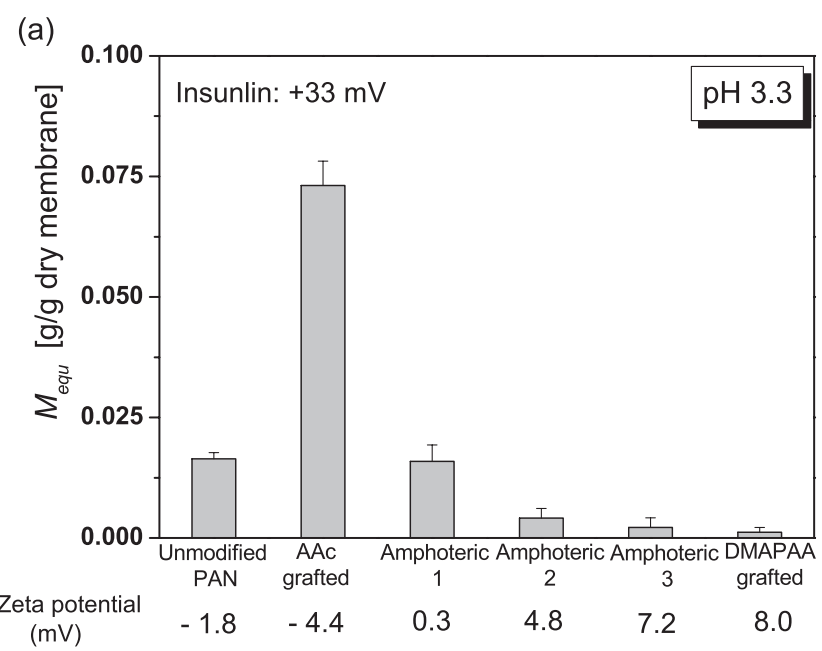

(b)

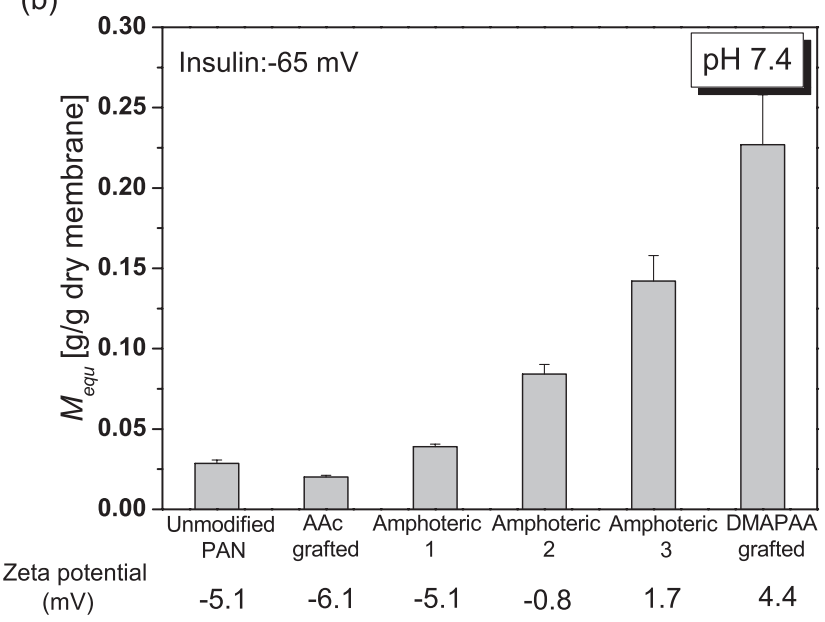

Figure 1. Insulin equilibrium adsorbed amount on the prepared membranes in (a) $10 \mathrm{mM}$ acetate buffer ( $\mathrm{pH}$ 3.3) and (b) $10 \mathrm{mM}$ Tris-HCl buffer (pH 7.4).

some adsorption of insulin on the membrane. This may be due to the inhomogeniety of the grafted layer on the membrane, and the hydrophobic interaction may also play a role to some degree. Here we should note that the association state of insulin, which can be affected by buffer and $\mathrm{pH},{ }^{26-29}$ also, might influence the insulin adsorption. ${ }^{6}$

\section{Adsorption Kinetics}

All the adsorption measurements showed similar time dependence; the adsorbed amount increased with time until reached the equilibrium. According to the equation for membrane sorption, ${ }^{30}$ insulin adsorption was analyzed by using eq 4.

$$
\frac{M_{t}}{M_{\infty}}=4\left(\frac{D t}{\pi l^{2}}\right)^{\frac{1}{2}}
$$

where $M_{t} / M_{\infty}$ is the fraction of insulin adsorption, $D$ is the diffusion coefficient, $t$ is time and $l$ is the membrane thickness. Figure 2 presents the kinetics of insulin adsorption plotted in coordinates of the sorption equation. At $\mathrm{pH} 3.3$, only curves 
(a)

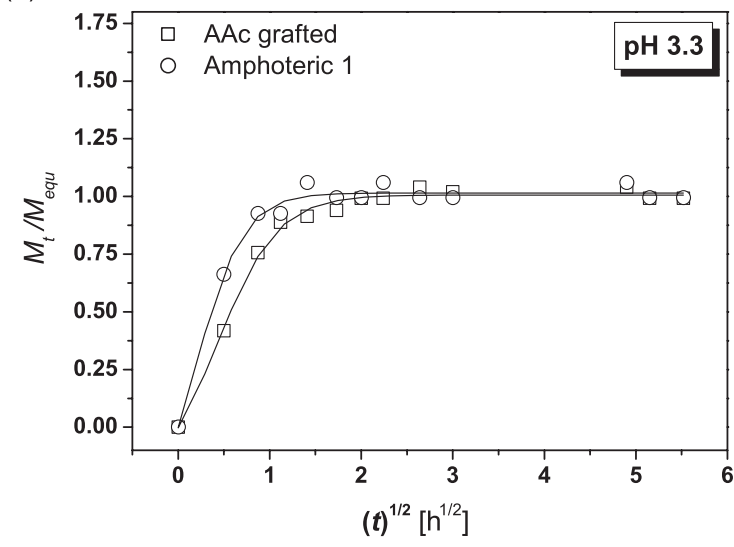

(b)

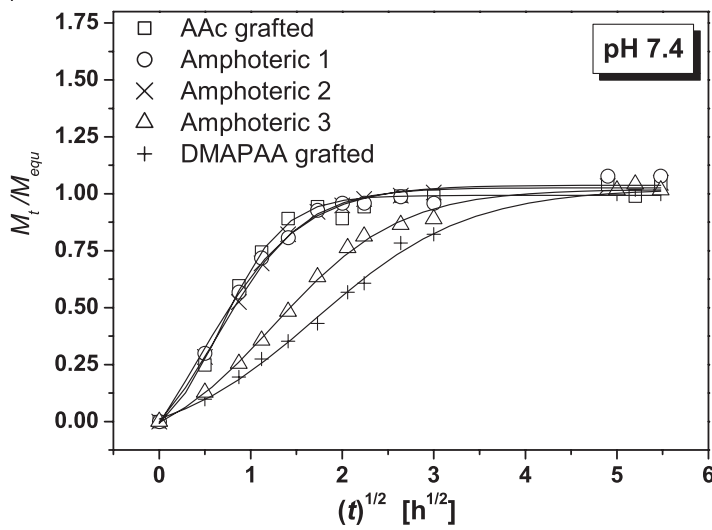

Figure 2. Insulin adsorption kinetics (a) at $\mathrm{pH} 3.3$ (10 mM acetate buffer) and (b) at $\mathrm{pH} 7.4$ (10 mM Tris- $\mathrm{HCl}$ buffer).

of AAc-grafted and Amphoteric-1 membranes are shown (Figure 2(a)), because insulin adsorbed amounts on Amphoteric-2, Amphoteric-3 and DMAPAA-grafted membranes were very low at this $\mathrm{pH}$ (as shown in Figure 1(a)), and the adsorption reached the equilibrium in a very short time, so that it was difficult to get a relationship between the adsorption fraction and time.

In the cases of AAc-grafted and Amphoteric-1 membranes at both $\mathrm{pHs}$ and Ampohteric-2 at $\mathrm{pH} 7.4$, insulin adsorption kinetics belongs to Fickian diffusion: the fractional adsorption $M_{t} / M_{\infty}$ was proportional to the square root of time at the early adsorption stage. However, the curves of Amphoteric-3 and DMAPAA-grafted membranes at pH 7.4 (Figure 2(b)) were sigmoid in shape, indicating an anomalous behavior. Under such conditions, the adsorption behavior seems to need more parameters to describe besides diffusion coefficient. One possible reason for the non-Fickian behavior is the reaction between insulin and the charge groups of the grafted polyelectrolyte chains when insulin and the membrane carried opposite charge. Such reaction changed the structure of the interface between the membrane and solution ${ }^{31}$ or the charge properties of the membranes, which makes the interfacial diffusion of insulin from the solution to the membrane become important in the insulin adsorption. As a consequence, insulin adsorption behavior changed with the adsorbed amount. Moreover, it seems that this effect is more remarkable when the adsorbed amount increased.

\section{CONCLUSIONS}

We focus on the amphoteric charged membranes as a material for insulin delivery system. A series of amphoteric charged membranes were prepared by grafting AAc and/or DMAPAA onto porous PAN membranes. By controlling the ratio of AAc to DMAPAA, the surface charge property of the amphoteric membranes can be designed. The adsorbed amount of insulin correlated well with the charge properties of the membranes and insulin. This result showed that the contribution of electrostatic interaction was dominant for insulin adsorbed amount. In addition, it revealed that the adsorption kinetics showed non-Fickian behavior when the insulin adsorbed amount increased to very high values. These results provided the fundamental information for amphoteric charged membrane-based controlled release of insulin. Further studies on transport of insulin through the amphoteric charged membranes are now in progress and will be published soon.

Acknowledgment. We express our great appreciation to Mr. Jun Okumura (Mitsubishi Rayon Co., Ltd., Japan) for kindly providing poly(acrylonitrile) powder.

Received: April 15, 2008 Accepted: May 23, 2008

Published: July 16, 2008

\section{REFERENCES}

1. S. Tokumoto, N. Higo, and K. Sugibayashi, Int. J. Pharm., 326, 13 (2006).

2. A. C. Sintov and U. Wormser, J. Controlled Release, 118, 185 (2007).

3. O. Pillai, S. D. Borkute, N. Sivaprasad, and R. Panchagnula, Int. J. Pharm., 254, 271 (2003).

4. Y. N. Kalia, A. Naik, J. Garrison, and R. H. Guy, Adv. Drug Delivery Rev., 56, 619 (2004).

5. L. Chu, Y. Li, J. Zhu, H. Wang, and Y. Liang, J. Controlled Release, 97, 43 (2004).

6. S. H. Mollmann, J. T. Bukrinsky, S. Frokjaer, and U. Elofsson, J. Colloid Interface Sci., 286, 28 (2005).

7. A. Nakajima and Y. Hata, Polym. J., 19, 493 (1987).

8. H. Matsumoto, Y. Koyama, and A. Tanioka, J. Colloid Interface Sci., 264, 82 (2003).

9. S. H. Mollmann, L. Jorgensen, J. T. Bukrinsky, U. Elofsson, W. Norde, and S. Frokjaer, Eur. J. Pharm. Sci., 27, 194 (2006).

10. T. Serizawa, K. Yamashita, and M. Akashi, Polym. J., 38, 503 (2006).

11. T. Jimbo, P. Ramirez, A. Tanioka, S. Mafe, and N. Minoura, J. Colloid Interface Sci., 225, 447 (2000).

12. P. M. Biesheuvel, P. Stroeve, and P. A. Barneveld, J. Phys. Chem. B, 108, 17660 (2004).

13. T. Jimbo, A. Tanioka, and N. Minoura, Langmuir, 14, 7112 (1998).

14. T. Xu, J. Membr. Sci., 263, 1 (2005).

15. H. Matsumoto, Y. Koyama, and A. Tanioka, Langmuir, 17, 3375 (2001).

16. P. Ramírez, A. Alcaraz, and S. Mafé, J. Electroanal. Chem., 436, 119 (1997).

17. T. Jimbo, M. Higa, N. Minoura, and A. Tanioka, Macromolecules, 31, 
1277 (1998).

18. T. Luxbacher, Desalination, 199, 376 (2006).

19. J. H. Lee, G. Khang, J. W. Lee, and H. B. Lee, J. Biomed. Mater. Res., 40, 180 (1998).

20. S. Lee, G. Hsiue, P. Chang, and C. Kao, Biomaterials, 17, 1599 (1996).

21. Y. Wada, H. Mitomo, K. Kasuya, N. Nagasawa, N. Seko, A. Katakai, and M. Tamada, J. Appl. Polym. Sci., 101, 3856 (2006).

22. C. Wang and J. Chen, Appl. Surf. Sci., 253, 4599 (2007).

23. E. Uchida, Y. Uyama, and Y. Ikada, Langmuir, 10, 1193 (1994).

24. K. Waizumi and S. Nawata, Journal of the Japanese Association for Crystal Growth, 33, 148 (2006).

25. S. Koutsopoulos, K. Patzsch, W. Bosker, and W. Norde, Langmuir,
23, 2000 (2007).

26. T. Nylander, in "Biopolymers at Interfaces," 2nd ed., M. Malsten Ed. Marcel Dekker, New York, 2003, Chapter 10.

27. Y. Pocker and S. B. Biswas, Biochemistry, 20, 4354 (1981).

28. V. Sluzky, J. A. Tamada, A. M. Klibanov, and R. Langer, Proc. Nat. Acad. Sci. U.S.A., 88, 9377 (1991).

29. A. Ahmad, V. N. Uversky, D. Hong, and A. L. Fink, J. Biol. Chem., 280, 42669 (2005).

30. J. Crank and G. S. Park, in "Diffusion in Polymers," Academic Press, London and New York, 1968, Chapter 1.

31. V. A. Kabanov, V. B. Kkobeleva, V. B. Rogacheva, and A. B. Zezin, J. Phys. Chem. B, 108, 1485 (2004). 